ARTíCULOS 



\title{
LA DIGITALIZACIÓN DE LA CONVERSACIÓN PÚBLICA: REDES SOCIALES, AFECTIVIDAD POLÍTICA Y DEMOCRACIA
}

The digitalization of public opinion: social networks, political sentiment and democracy

\author{
MANUEL ARIAS MALDONADO \\ Universidad de Málaga
}

Cómo citar/Citation

Arias Maldonado, M. (2016). La digitalización de la conversación pública: redes sociales, afectividad política y democracia.

Revista de Estudios Políticos, 173, 27-54.

doi: http://dx.doi.org/10.18042/cepc/rep.173.01

\section{Resumen}

Este trabajo aborda el impacto de las nuevas tecnologías de la comunicación sobre la democracia. Y lo hace mediante el análisis del proceso de digitalización de la conversación pública, por entender que ésta es decisiva —en los regímenes de opinión - para la calidad del proceso político democrático. Se atiende por ello primordialmente al efecto que produce sobre los ciudadanos el empleo de las redes sociales y demás plataformas digitales, en el marco de una concepción de aquellos como sujetos afectivos influidos por sus emociones y sensaciones preconscientes. Se defiende la tesis de que las redes digitales son tecnologías intrínsecamente afectivas cuya influencia sobre la intelección y la acción política obliga a reconsiderar las concepciones vigentes sobre las democracias liberales realmente existentes.

\section{Palabras clave}

Democracia; redes sociales; tecnología; digitalización; afectos; emociones políticas; opinión pública.

\section{Abstract}

This article deals with the impact of new communications technologies on democracy. It does so by analysing the processes by which public opinion is being 
partly digitalized - on account of the decisive importance that the quality of public opinion possesses for the quality of democracy. The focus is on the effects of citizens' usage of social media and other digital platforms. Citizens themselves are mainly considered as affective subjects influenced by their own emotions and preconscious sensations. Social networks turn out to be intrinsically affective technologies, whose strong influence on political socialization and mobilization forces us to reconsider current understandings of actually existing liberal democracies.

\section{Keywords}

Democracy; social networks; technology; digitalization; affects; political emotions; public opinion. 


\section{SUMARIO}

I. INTRODUCCIÓN. II. FENÓMENOS DE LA ATENCIÓN: DE LA DIGITALIDAD A LA AFECTIVIDAD. 1. El giro digital. 2. El giro afectivo. III. LA DIGITALIZACIÓN DE LA OPINIÓN PÚBLICA. 1. Del ciudadano sentimental a los público afectivos. 2. Virtudes de la digitalización. IV. MUTACIONES DEMOCRÁTICAS EN LA ERA DIGITAL. V. CONCLUSIÓN. BIBLIOGRAFÍA.

\section{INTRODUCCIÓN}

No cabe duda de que los últimos años han sido fértiles en acontecimientos políticos de gran resonancia pública: de la crisis del euro al referéndum escocés, de los atentados islamistas al problema migratorio, del ascenso de los populismos a los problemas de gobernabilidad postelectoral. En sí mismos, no constituyen una novedad radical; la historia abunda en momentos críticos. Sin embargo, la sociedad que los produce ha cambiado por efecto de las nuevas tecnologías de la información y eso está produciendo una transformación en el modo en que los fenómenos políticos son recibidos, percibidos y discutidos en la esfera pública. En cada uno de esos casos, especialmente con motivo de sucesos concretos que intensifican las comunicaciones - ya se trate de un atentado, un referéndum o un debate televisado-, se dejan ver con claridad las consecuencias más aparentes de la digitalización de la esfera pública: en paralelo al suceso tiene lugar un debate a través de las redes sociales cuyos rasgos dominantes son la polarización ideológica y la afectividad expresiva. Simultáneamente, esas redes producen por sí mismas efectos políticos facilitando la difusión de campañas de todo tipo y propiciando la movilización de públicos emergentes alrededor de las mismas: apoyo a movimientos de austeridad como el 15M, a grupos xenófobos como Pegida, reprobación pública de quienes incurran en gaffes amplificados digitalmente. A ello habría que sumar las herramientas que proporciona para la captación de futuros miembros de movimientos políticos y grupos terroristas, como el fenómeno del yihadismo ha demostrado sobradamente. En un sentido más amplio, la digitalización ha transformado el entorno en que se desenvuelven nuestras vidas cotidianas y, con ello, alterado el modo en que se configuran nuestros regímenes de percepción.

Pues bien, no es en absoluto casual que esta transformación de la esfera pública —y por tanto de las democracias que las albergan— coincida con dos 
de los desarrollos más reseñables que han venido experimentado las ciencias sociales en los últimos años: por un lado, el giro digital que trata de dar cuenta del impacto social de las nuevas tecnologías de la información; por otro, el giro afectivo que se propone desvelar el papel que las emociones juegan en la constitución y desenvolvimiento del sujeto político y, por lo tanto, de la propia democracia. Digitalidad y afectividad se nos aparecen así como fenómenos cuya comprensión se hace imprescindible para iluminar el proceso de cambio que están experimentando nuestras sociedades; un proceso impulsado en gran medida por el primero de ellos, pero cuyo curso puede verse influido considerablemente por el segundo: una sociedad que otorgue de manera estructural más importancia a los contenidos afectivos que a los racionales —bien sea espontáneamente o a través del proceso político- corre ciertos riesgos que conviene tener presentes y empezamos a apreciar: polarización del debate público, dificultad para el acuerdo político, tendencia al hiperliderazgo y el plebicisto de facto. A cambio, puede también ofrecer algunas oportunidades si con ello se logra una mayor inclusión y participación ciudadana. En cualquier caso, es importante subrayar que digitalidad y afectividad no son dos procesos separados que influyen de manera independiente sobre la sociedad que los produce. Ya que las redes sociales que hacen posible el poliálogo ciudadano son un medio particular de comunicación caracterizado por su afectividad, o lo que es igual, por servir como vehículo privilegiado de transmisión y difusión de contenidos afectivos y para la consiguiente formación de públicos afectivos que se relacionan emocional y expresivamente con los asuntos públicos de su interés o hacia los que su interés es atraído mediante el contagio viral propio de las redes. Desde este punto de vista, la digitalización produciría un efecto de sentimentalización sobre la conversación pública y con ello sobre la democracia representativa.

A la exploración de este problema se dedica este artículo, que se estructurará como sigue. En primer lugar, se aclarará el sentido en que puede hablarse de los dos giros mencionados en la ciencia social: el digital y el afectivo. A continuación, se describirá el ideal normativo de la opinión pública, a fin de que puedan situarse en su debido contexto los cambios provocados en ella por las nuevas tecnologías de la información. En tercer lugar, se describirán las patologías de la conversación digital, con especial atención a su dimensión afectiva. Sus posibles efectos benéficos serán también discutidos, con objeto de evitar cualquier tentación catastrofista. En cuarto lugar, se discutirán las consecuencias que tiene para la democracia el doble proceso de la digitalización y la sentimentalización, prestándose especial atención a dos nociones relacionadas que tratan de capturar las singularidades de aquellas: las de democracia «ocular» y democracia «sensorial». Una conclusión cierra el trabajo. 


\section{FENÓMENOS DE LA ATENCIÓN: DE LA DIGITALIDAD A LA AFECTIVIDAD}

Es razonable afirmar que se ha desarrollado en la esfera académica una suerte de industria giratoria, merced a la cual los así llamados giros o cambios de paradigma se suceden unos a otros a velocidad endiablada. Hemos conocido así los venerables giros lingüísticos, pragmático y simbólico, que habrían dado paso en su momento a un giro cultural y narrativo que coexistió con el postcolonial, hasta que los giros sociales, afectivo, mediático y semántico hubieron preparado el terreno para un giro digital que es, también, cooperativo y de movilidad. Si una etiqueta tiene éxito, al fin y al cabo, sus promotores se convertirán en estrellas dentro del gremio, razón por la cual merece la pena intentarlo. La contrapartida es que esta sucesión de maniobras terminan por producir una cierta fatiga metodológica cuyo efecto colateral es restar verosimilitud a las nuevas anunciaciones teóricas (cfr. Hug, 2013). Al menos, de entrada; esto es, hasta que no se haya verificado la solidez de la propuesta correspondiente. Ha de dilucidarse por ello brevemente si los giros aquí atendidos —el digital y el afectivo — tienen plausibilidad suficiente: si está justificado darles carta de naturaleza en atención a los fenómenos descritos y al movimiento por ellos provocado dentro de su campo de conocimiento, o se trata, por el contrario, de una exageración publicitaria producida en el ámbito de las ciencias sociales. Huelga decir que nos limitaremos a bosquejar el contenido de cada uno de estos desplazamientos de la atención teórica, sin profundizar en sus implicaciones.

\section{EL GIRO DIGITAL}

En principio, la difusión de Internet fue rápidamente saludada como demostrativa de una «segunda era mediática» (Poster, 1995), consolidando la época de los «nuevos medios» (Flew, 2002) en el marco de la «era de la información» (Webster, 2006) y la «sociedad red»(Castells, 1996). Su novedad principal es que no se trata sólo de medios receptores, sino de un sistema de comunicación entre individuos que adopta forma reticular. Manuel Castells (2008) ha hablado al respecto del tránsito de los medios de comunicación de masas, verticales y unilaterales, a una autocomunicación de masas donde los propios consumidores se convierten ahora, simultáneamente, en productores: eso que designa con la espantosa palabra "prosumidor». En las ciencias sociales, Internet se considera intrínsecamente diferente de otras tecnologías de masas, porque su interfaz está individualizada y su estructura es descentralizada (Cavanagh, 2007; Fuchs, 2008). Para unos, el giro digital es un resultado de la globalización y de la expansión de las tecnologías de la comunicación; 
para otros, el giro digital es una variación del más amplio "giro mediático». Y no faltan voces que sostienen que la innovación tecnológica ha sufrido un retroceso en nuestra época, comparada con la cualidad revolucionaria de disrupciones anteriores. Morozov (2013), por ejemplo, minimiza la importancia de las nuevas tecnologías digitales y acusa a los defensores del giro en cuestión de hacer «epocalismo", por cuanto sólo tienen ojos para las novedades y no para las lógicas continuidades con el inmediato pasado sociotécnico.

Sin embargo, parece sensato reconocer la existencia y el impacto de un giro digital, por el que hay que entender simultáneamente un proceso de digitalización de las economías, la cultura y la política, así como una atención creciente de las ciencias sociales hacia el mismo. Su verosimilitud se asienta, al menos, en las siguientes razones: i) nuestras vidas están cada vez más medidas por las tecnologías digitales y la propia subjetividad está cambiando en consecuencia; ii) las formas tradicionales de organización política, cultural y económica están transformándose por efecto de la digitalización; iii) la producción y reproducción social del conocimiento se están viendo alteradas y adoptan formas hasta ahora inéditas; y iv) la digitalización produce ideologías propias que modifican nuestra percepción de la realidad y de nosotros mismos, así como novedosas costumbres y formas de interacción.

Se diría así que estamos al comienzo de un cambio en los estándares que gobiernan los problemas, conceptos y explicaciones dominantes, así como en plena transformación de las condiciones de posibilidad para la generación, transmisión, acceso y preservación del conocimiento. Decisivamente, en los últimos años habríamos vivido una era de "exuberancia informativa» (Chadwick, 2009), concepto que alude a la disposición creciente de los ciudadanos a producir, reproducir y compartir contenidos mediáticos, con el propósito - consciente o no- de crear bienes públicos para la organización y coordinación política formal e informal. No hace falta añadir que las redes sociales, ambiguas en su estatuto a la vez privado y público, han sido las protagonistas principales de este fenómeno. Adicionalmente, este desarrollo de la conectividad y de las tecnologías móviles — por no hablar de una revolución computacional menos visible - sugiere la necesidad de plantear un debate riguroso sobre el nacimiento de una cultura que es, a la vez, global y posthumana. Por una parte, un conjunto de culturas heterogéneas interactúan en un mundo globalizado y conectado en red gracias a las tecnologías de la información: la globalización modifica prácticas y culturas locales, mientras los medios digitales alteran y reconstruyen la identidad y las relaciones sociales y políticas en un sentido más amplio. Por otra, ya no existen ni el sujeto ni la máquina por separados, sino que ambos operan juntos a la manera de un híbrido. Tal como se pregunta Lev Manovich (2014): «¿Qué es la cultura después de ser 'softwarizada??». Hay pocas dudas, pues, de que el giro digital ha tenido lugar. 


\section{EL GIRO AFECTIVO}

Por su parte, el giro afectivo en las ciencias sociales describe la atención creciente que estas vienen prestando en los últimos años al conjunto de procesos preconscientes o espontáneos que, bajo la denominación general de afectos, ejerce su influencia sobre los individuos a la hora de percibir la realidad y desenvolverse en ella. Esto supone una expansión del ámbito de estudio de las ciencias sociales, cuya atención se vuelve hacia los sentimientos, los recuerdos, la vida cotidiana, la esfera de lo material (Wetherell, 2012: 2). Y aunque es verdad que este análisis del sujeto - y de los efectos agregados que los afectos individuales producen en el orden colectivo- es continuación de los viejos temores sobre las limitaciones de nuestra racionalidad, la novedad estriba en el carácter multidisciplinar de los esfuerzos en curso, con mención especial para las aportaciones que provienen de las neurociencias y la psicología política informada por ella.

Topamos aquí con una paradoja. El relativo olvido en que cayeron las emociones dentro de las ciencias sociales durante las décadas de los años setenta y ochenta puede explicarse por dos razones: primero, que se las consideraba elusivas y refractarias a la indagación científica; segundo, se asumía que la modernización social las iría relegando a un papel secundario (Brader y Marcus, 2013: 265). Pero no ha sucedido ni lo uno ni lo otro, sino lo contrario. Si las neurociencias han suministrado nuevas herramientas de análisis, la polarización política y la influencia de las nuevas tecnologías de la información, en conjunción con una cultura cada vez más audiovisual y menos escrita, han devuelto a las emociones un papel prominente en la articulación de la opinión pública, al tiempo que se producía una relegitimación de las formas emocionales de expresión en la esfera privada y aun en la expresión artística. Si las nuevas tecnologías producen el giro digital en las ciencias sociales, su equivalente afectivo responde a una doble causa: a la nueva prominencia de los afectos en las democracias avanzadas y al hecho de que las ciencias sociales y las humanidades han llegado a ellas en el curso de su programa epistemológico, elemento central al cual es la sospecha sobre las dobleces de la razón liberal o ilustrada. Esta, en fin, se redescubre cercenada por la influencia de las emociones, las patologías del razonamiento o los espejismos de la percepción.

No se trata de otorgar a la emoción el mando de nuestra cabina decisoria, sino de sugerir que razón y emoción son dos sistemas complementarios que se alternan en nuestro cerebro para la toma de decisiones complejas: uno es lento pero preciso, el otro es rápido e impreciso. Es lo que viene a decir Daniel Kahneman (2011) cuando describe dos sistemas de toma de decisiones: el Sistema 1, intuitivo y rápido, en sus distintas variantes; y el Sistema 2, basado en la pausada deliberación interna con empleo de la información disponible. 
Pero, como él mismo apunta, la emoción juega ahora un papel mucho más importante en nuestras explicaciones sobre los juicios intuitivos y la toma de decisiones de lo que solía. Evidentemente, el problema estriba en determinar cuál es el peso relativo de cada uno de estos elementos de la subjetividad, tanto consciente como preconsciente, en su desenvolvimiento (cfr. Neuman et al., 2007). Esto significa, entre otras cosas, que no somos agentes soberanos (Krause, 2011). Ya que el yo protagonista de la agencia individual no ejerce pleno control de su actividad. Y si la agencia puede definirse como la afirmación de la existencia subjetiva mediante la acción en el mundo, su protagonista resulta ser un sujeto reflexivo y capaz, pero no soberano. Emergen de aquí dos grandes temas: el papel del afecto como motor del comportamiento (función de motivar, dirigir, priorizar el cerebro) y la compleja interacción de afecto y cognición (cfr. Scherer, 2005). Hablamos, pues, de estudiar el modo en que los ciudadanos, mezclando impulso y cálculo, deciden qué les es políticamente significativo. Y de ahí, huelga decirlo, su importancia para la teoría política.

A la hora de trazar un retrato del ciudadano sentimental, habría que comenzar por advertir que condenar la emoción no sirve para nada, ni tiene sentido del todo. No es tanto que la emoción tenga razones que la razón no entiende, sino que no pueden desligarse una de otra tan fácilmente. Patrick Miller (2011) ha señalado incluso que el compromiso político suele ser un fuerte desencadenante de emociones, y que éstas no deben ser vistas necesariamente como un elemento que ciega o distorsiona el juicio racional: la emoción interactúa con la reflexión y la motivación, especialmente en aquellos ciudadanos más sofisticados políticamente. No podemos, pues, escapar de las emociones. Tal como la citada obra de Kahneman ha demostrado, lo que opera dentro de nosotros es una dualidad de sistemas, uno intuitivo y otro reflexivo, que compiten por tomar el control de nuestras decisiones. Sin duda, el primero está mucho más informado por las emociones que el segundo, que es el que corrige, si le es posible, al primero: el primero quiere fumar hoy, el segundo quiere tener una larga vida mañana. Pero nuestra reflexión no está libre de la influencia de las emociones $y$ los sesgos cognitivos e informacionales.

Pese a ello, la cognición es más costosa y lenta, razón por la cual tendemos a trabajar mediante una toma de decisiones intuitiva o emocional cuando nos encontramos bajo presión. Y cuando la razón y las emociones colisionan, ganan invariablemente estas últimas, tal como Westen ha puesto de manifiesto en su estudio sobre «el cerebro político». A su juicio:

El cerebro politico es un cerebro emocional. No es una máquina de cálculo desapasionada, que busca objetivamente los hechos, datos y políticas correctas para tomar una decisión razonada (2007: xv). 
Más aún, esta propensión emocional puede predicarse también de los ciudadanos más cultivados y presuntamente autónomos: a cada cual, pues, sus sesgos. $\mathrm{Y}$ aunque las emociones suelen proporcionar una guía adecuada para las decisiones -incluidas las electorales - son muchos los sesgos del voto individual que generan problemas colectivos. Baste pensar qué pocas probabilidades de victoria tiene un candidato que diga la verdad o haga una campaña llena de malas noticias. A ello hay que sumar el efecto distorsionador que produce la falta de información por parte de la mayoría de los votantes, variable que no carece de importancia. Tal como ha documentado Popkin (1994), el votante suele tener unas creencias prefijadas que trata de apuntalar, por lo general, con el mínimo posible de información; de ahí que lo describa como un «avaro cognitivo». Por eso, como ha explicado convincentemente Giovanni Sartori (2005), tampoco el votante real tiene mucho que ver con el votante ideal: si éste es un sujeto pragmático que construye sus preferencias a partir de la información, aquél ignora los asuntos concretos y se adhiere a imágenes de partido con las que mantiene una relación sentimental (si no identitaria: ser de izquierdas, ser de derechas). El votante medio es así un gran simplificador de la realidad. Y como tal, una criatura sensible al impacto de categorías simplificadoras como la casta, los inmigrantes o el capitalismo. El votante racional es así un mito más que una realidad (Caplan, 2008).

Aspecto determinante de la afectividad política, por lo demás, es la pertenencia ideológica: el sentimiento de identificación con un grupo que implica la descalificación de sus rivales. Para Joshua Greene (2013) este problema tiene un origen evolutivo: los mismos mecanismos que han facilitado la cooperación intragrupal dificultan sobremanera la cooperación intergrupal, separando a los grupos humanos en distintas «tribus morales» con valores diferentes. Greene identifica las tendencias psicológicas que exacerban el conflicto intertribal - desde una tribalidad innata al ser humano hasta formas sesgadas de equidad- y, parafraseando a Kahneman, distingue entre una moralidad lenta y una moralidad rápida: la primera está ligada a la cognición y la segunda a la intuición, ganando una en flexibilidad lo que la otra tiene de eficiente. Para Jonathan Haidt (2012), el instinto tribal, que facilita la cooperación intragrupal, condiciona nuestra percepción de los hechos y los valores, de forma que sobrestimamos las virtudes propias y magnificamos los defectos ajenos, a menudo sin ser conscientes de estar haciéndolo. Pensemos en la indulgencia con la corrupción de los propios, rápidamente convertida en dureza contra la ajena. Pero lo relevante es que esa adscripción tribal resta importancia al contenido de las creencias, para otorgársela a los sentimientos que experimentamos: hacia dentro y hacia fuera. Más bien, las creencias concretas servirían como un pretexto, una justificación racional de las emociones que nos lleva a rechazar a quienes pertenecen a un grupo distinto qua distinto. 


\section{LA DIGITALIZACIÓN DE LA OPINIÓN PÚBLICA}

Sin duda, uno de los lugares - aunque no sea un lugar en sentido estricto- donde la sentimentalización de la democracia se deja ver con más claridad es la esfera pública, es decir, allí donde se desarrolla la conversación pública que es, a la vez, creadora de opinión con influencia sobre el gobierno y sobre los ciudadanos, así como parte del proceso político en tanto esfera de creación y transmisión de significados y percepciones. Tiene así plena lógica que las transformaciones en la esfera pública, que lo son también del modo en que se desarrolla la conversación colectiva, hayan de ser observados con atención: el tono de la opinión pública constituye la atmósfera en que se desenvuelve la democracia. Y en nuestros días, desencadenada ya de forma abierta la revolución de las tecnologías de la información, es necesario preguntarse cuál es el impacto de la digitalización sobre la conversación pública, lo que supone discernir la medida en la cual esta conversación pública contribuye a exacerbar los sentimientos de sus integrantes o incrementa, por el contrario, sus contenidos de razón estructurando el debate con arreglo a reglas orientadas a tal fin. A sabiendas, valga la cautela, de que no ha existido aún ni existirá jamás una democracia asentada en un impecable uso público de la razón.

Sabido es que la esfera pública está formada por un conjunto de instituciones políticas, prácticas y actividades cuyos participantes intercambian ideas sobre asuntos de interés público. Es verdad que existen notables discrepancias en la literatura acerca de la modernidad o antigüedad del fenómeno y sobre los contornos precisos de la misma (cfr. Ward, 2014). Habermas (1981), autor del estudio de referencia sobre su evolución histórica, excluye de ella a las familias y los mercados, a pesar de que podría argüirse que las primeras son un espacio de socialización y conversación privada con una clara influencia sobre las percepciones sociales y que el mercado posee virtudes epistemológicas indudables por mor de su capacidad para transmitir información sin necesidad de una distribución centralizada. Por otro lado, aunque la institucionalización de la función de la opinión pública en las democracias representativas hubo de esperar a la transformación ilustrada del fenómeno, ligado a la aparición de nuevas formas de conversación y difusión de las opiniones, parece probado que la pubblica voce de Maquiavelo, antes vox populi romana, no dejaba de cumplir una función en los regímenes políticos precedentes; una función, cabe decir, aún más difusa de la que cumplen hoy dada la ausencia de mecanismos democráticos de elección que obligasen a los gobernantes a buscar el apoyo de los ciudadanos, que no obstante les convenía recabar para no convertirse a sus ojos en tiranos susceptibles de ser resistidos mediante la rebelión. Por lo demás, que el papel de la opinión pública en las democracias liberales no pueda ser institucionalizado de manera más 
precisa responde a su propia naturaleza amorfa y dinámica, además de a elementales cuestiones de escala.

Desde sus mismos orígenes, pertenece al campo semántico de la opinión pública la idea de que las posiciones públicas han de fundamentarse. Hay una dimensión prescriptiva del concepto que remite a la forma en que el debate público debería conducirse, que tal vez habría de entenderse como la aspiración a extender al conjunto de la opinión pública el modo en que siempre se han conducido algunos segmentos de la misma, en contraposición a formas menos sofisticadas de comunicación no por ello menos importantes en la formación de la opinión pública: desde la profecía al grafiti. Hablamos así de un ideal y de una práctica. A este respecto, en su indagación histórico-conceptual, Lucian Hölscher (1978) ha puesto de manifiesto cómo son las nuevas instituciones burguesas —conciertos públicos, teatro, revistas morales y satíricas, salones - las que permiten el desarrollo de una nueva esfera pública a la que se proporciona un nuevo valor estético, moral y racional. Son aquellos espacios en los que el público instruido se comunicaba entre sí, limitación de entrada que relativiza la dimensión propiamente pública del fenómeno. Ya en el siglo XVIII, se ha consolidado la idea del público como sociedad burguesa educada:

El público era un colaborador ficticio, que podía encontrarse en libros y revistas en forma de clientes y amigos, al que se podía llamar como testigo en los conflictos de opinión y era sobre todo reconocido como juez capaz de dar la opinión final en toda clase de contiendas callejeras (Hölscher, 1978: 437).

Sucede que la intensificación de las comunicaciones — su adensamiento progresivo — dio paulatinamente realidad a esa ficción, constituyéndose así una «sociedad» dentro de la sociedad formada por aquellos de entre sus miembros capaces de tomar parte en la conversación pública con los medios disponibles en su época. También entonces se añade a la idea de público una dimensión política que nunca lo abandonará: el público como parte activa de la vida pública del Estado. La esfera pública lingüística fue considerada por los ilustrados como racional y egalitaria, pudiendo así entenderse como modelo para una esfera pública política igualmente racional y egalitaria. Hölscher cita una significativa sentencia de Johann Michaelis, quien escribía en 1759 que «la lengua es una democracia» [Die Sprache ist eine Demokratie]. Y una democracia, se suponía, de calidad.

Doscientos cincuenta años después, no somos tan optimistas. El colapso de las democracias liberales en el período de entreguerras y el triunfo de unos totalitarismos más que dotados para la manipulación propagandística de las opiniones públicas quebrantó para siempre la fe en la capacidad civilizadora 
de la conversación colectiva. No porque esa capacidad no exista, sino porque nada garantiza que pueda lograr sus objetivos ni impide el desmoronamiento por la pendiente opuesta de la descivilización. En el conocido ensayo de George Orwell (2000) sobre la relación entre el lenguaje y la política, ha desaparecido todo rastro democrático del primero debido a su colonización por la segunda: ideologías y partidos privan a las palabras de todo significado claro, a la vez que demandan una adhesión de sus simpatizantes que impide la búsqueda de la verdad que llama a las cosas por su nombre. Por su parte, Victor Klemperer (2007) registró minuciosamente el gradual envenenamiento del pueblo alemán por medio del lenguaje contaminado del nazismo. Súmese a eso la crítica que autoras como Nancy Fraser (1992) o Jane Mansbridge (1990) elevan contra el ideal deliberativo ilustrado - por la cualidad excluyente que poseen las diferencias de estatus y competencia cognitiva entre distintos ciudadanos- y comprobaremos que la esfera pública de raigambre ilustrada goza, al menos aparentemente, de mala salud. En gran medida porque, como reconoce el propio Rawls cuando plantea la necesidad de que las contribuciones de los ciudadanos a las discusiones públicas se ajusten a ciertas reglas, no puede obligarse a nadie a respetarlas, sino solamente confiar en que cada uno se esforzará en hacerlo cumpliendo un «deber de civilidad» (Rawls, 1993: 217). Pero es un deber moral que adopta la forma de una cortesía interactiva, no una obligación legal exigible ante tribunal alguno.

Pues bien, ese deber de civilidad parece estar más ausente que nunca de las esferas públicas occidentales desde que este tiene lugar mayormente online a través de las nuevas tecnologías de la información. A través de distintos instrumentos que van desde las redes sociales hasta los blogs y las secciones de comentario adosadas a las distintas webs de información y opinión, asistimos a una suerte de creación en vivo de la opinión de la que los ciudadanos pasan a ser co-protagonistas. La era de la comunicación vertical de masas ha dejado paso a una mayor desarticulación del proceso de creación de la opinión pública en la que los medios tradicionales coexisten con ese fenómeno que Manuel Castells (2008) ha llamado, muy perceptivamente, «la autocomunicación de masas», caracterizada por la activa participación de los propios ciudadanos en la creación y difusión de contenidos, que a su vez pueden ser comentados instantáneamente en ambas direcciones. Por supuesto, cada instrumento digital posee sus propias características, que dan lugar a diferentes subtipos conversacionales: no es lo mismo Twitter que Facebook, ni participar en estas plataformas es lo mismo que hacer comentarios a un blog o a una noticia periodística. Pero pueden describirse algunos rasgos que caracterizan el uso dominante de todas ellas, aun cuando las conclusiones que puedan extraerse al respecto no dejen de adolecer de cierta provisionalidad, dada la novedad de las herramientas en cuestión - bien podemos estar en una fase de juego social con 
las mismas para familiarizarnos mejor a ellas-. Tampoco, dicho sea de paso, deberíamos tomar estas formas de comunicación como novedades absolutas sin precedentes, porque los hay, en distintas formas: desde los grafitis que servían para comunicar mensajes de toda índole en los muros de las ciudades romanas hasta las frecuentísimas cartas diarias que intercambiaban con sus amigos Séneca o el vizconde de Valmont, a la manera de la mensajería instantánea de ahora mismo (cfr. Standage, 2013).

\section{DEL CIUDADANO SENTIMENTAL A LOS PÚBLICO AFECTIVOS}

¿De qué manera se ven potenciados o atenuados estos rasgos afectivos en la esfera pública por efecto de la influencia de las nuevas tecnologías que, sobre todo mediante las redes sociales, se han convertido en mediaciones decisivas en la relación del ciudadano con la vida política? La hipótesis más plausible es que un ciudadano ya propenso de suyo a la sentimentalidad - en el sentido de sujeto sometido al efecto político de sus afectos- se vuelve aún más sentimental con el uso de las nuevas tecnologías de la información. Estas son por tanto redes afectivas, cuyo uso por parte de los ciudadanos es mayormente expresivo o heurístico en lugar de deliberativo; algo que también puede interpretarse como benéfico en la medida en que un mayor número de ellos se implica en la vida política adhiriéndose a comunidades políticas fluidas más o menos transitorias. Pero atendamos primero a las patologías de la conversación digital.

Hay que arrancar del hecho de que la eclosión de los medios digitales han provocado la fragmentación de la oferta informativa; vale decir, también, de la oferta de sentido. Y esa fragmentación habría privado a los medios tradicionales de masas de su monopolio relativo sobre la opinión. Dado que esos medios tradicionales tienden a ejercer, por su capacidad aglutinadora, una función moderadora de la opinión pública, su debilitamiento ayudaría a explicar la radicalización creciente de la opinión pública. De donde resulta la pregunta de si esta fragmentación creciente de la conversación pública no da lugar a un pluralismo demasiado agudo, para el que la democracia representativa todavía no habría encontrado solución: un pluralismo agresivo que desemboca con facilidad en maneras vetocráticas.

Para muchos comentaristas, el desorden conversacional que ha seguido a la consolidación de las nuevas tecnologías quizá no compensa la ganancia en libertad de expresión y de acceso a la información que sin duda suponen. La pérdida de las mediaciones y los filtros que ejercían los medios tradicionales de comunicación y la propia restricción estructural que imponía una tecnología más limitada habría terminado por generar una cacofonía digital. Desde este punto de vista, el ciudadano no haría tanto uso de la razón como se embarca- 
ría en un uso expresivo de las redes, satisfaciendo sus necesidades emocionales pero dificultando el debate público racional sobre los asuntos de interés general. Más que una conversación, tendríamos ruido: todos hablan a la vez, pero nadie escucha a los demás. Pensemos en el fenómeno de los trolls, usuarios que dinamitan los intercambios digitales con una retórica incendiaria o la simple obstrucción de la conversación ajena. No son pocos los medios que han decidido eliminar la sección de comentarios ligada a sus noticias por la imposibilidad de combatir eficazmente esta plaga digital.

Habríamos accedido así a una «democracia de enjambre» (Han, 2013), una sumatoria privada de muchedumbres reactivas, que se mueven a base de flujos de halago o descalificación y que, como un seísmo, sacuden el espacio público llenándolo de ruido e impiden, la mayoría de las veces, una reflexión serena. Más que una deliberación racional e informada, las redes funcionan amplificando y modulando una atmósfera, un estado de ánimo público, que crea las condiciones — con su suave presión — donde el sentimiento y las acciones individuales y colectivas tienen lugar, y donde operan gobiernos, empresas, ONGs, universidades, etc. No habría tanto persuasión como contagio. De ahí la metáfora del virus, en su acepción informática y cultural: going viral. Aun cuando, como ha puntualizado Margaret Wetherell (2012), es necesario precaverse contra el uso de esta metáfora en el contexto social, por cuanto ese contagio solo tendría lugar allí donde existe una previa identificación compartida con determinadas prácticas o posiciones: la tribu moral a la que pertenecemos o a la que nos incorporamos.

A este respecto, la viralidad digital ha contribuido también a intensificar un fenómeno de sentimentalización política que, aunque preexistente en otros formatos, ha desbordado a las esferas públicas nacionales para conectar entre sí a ciudadanos de todo el mundo: la solidaridad cosmopolita de coste cero expresada a través de una adhesión digital. Es una solidaridad que no puede entenderse desligada de la disminución de sus costes, que banalizan el compromiso e incluso lo hacen divertido en sus formas; es el llamado slacktivism o activismo del vago: un doble click desde el salón de casa basta para alinearnos con causas nacionales o globales donde el deslindamiento de la razón y la sinrazón morales es tan diáfano como, por ello mismo, íntimamente satisfactorio (cfr. Gladwell, 2010).

Por otro lado, la fragmentación de la opinión pública puede producir un efecto reductor de la cohesión social, al dificultar el contacto entre distintos grupos de opinión y radicalizarse las opiniones propias al no enfrentarse nunca a sus contrarias. Dado que no hay una red social, sino que dentro de estas elegimos a nuestros interlocutores, se ha dicho que constituyen «cámaras de resonancia» donde solo escuchamos el eco de nuestra propia voz (Sunstein, 2008). Se trata de un «efecto silo» que separa a los ciudadanos en grupos que 
no se comunican entre sí. Y lo mismo se ha dicho de la blogosfera, un espacio altamente compartimentalizado donde los autores suelen vincular artículos que reflejan puntos de vista similares, reforzando las disposiciones previas del público en lugar de desafiarlas (Reese et al., 2007). Todo lo cual produciría un efecto polarizador en la conversación pública. Esta «balcanización» remite a la «tiranía de la opinión pública» profetizada por Alexis de Tocqueville (2005) en 1835 tanto como al efecto de los nuevos medios de comunicación sobre nuestra conciencia colectiva que temiera Marshall McLuhan (1962), quien ya en los años sesenta advirtió que la «aldea global» podía ser un lugar claustrofóbico y desagradable. Un buen ejemplo de todo lo anterior -o sea: del enjambre, el contagio, el modo sentimental, la tiranía de la opinión - son las mencionadas shitstorms o, literalmente, tormentas de basura que caen sobre un personaje público o semipúblico a raíz de una acción o declaración desafortunadas. Para Byung-Chul Han, estos ataques colectivos son solamente la manifestación más extrema de un problema más amplio, a saber, la eliminación de la distancia entre los interlocutores digitales, que desemboca en una falta de respeto entre ellos a la hora de comunicarse entre sí que el frecuente anonimato de sus perfiles online no hace sino agravar:

El respeto presupone una mirada distanciada, un pathos de la distancia. Hoy en día, se abandona a una exhibición sin distancia, característica del espectáculo. [...] El respeto es la piedra angular de la esfera pública. Si aquel se debilita, esta se deteriora (Han, 2013: 7).

Esta ausencia de distancia refuerza la dimensión afectiva de las redes sociales, que facilitan por su propia naturaleza «sentimientos de implicación» (Gregg, 2011). Tal como expone Zizi Papacharissi (2015: 4), los nuevos medios inducen a interpretar las situaciones «sintiéndonos como aquellos que las experimentan, incluso aunque en la mayoría de los casos no podamos pensar como ellos». De ahí que, a su juicio, las estructuras digitales reticulares que nos permiten expresarnos y conectarnos se caracterizen por su afectividad, dando lugar por ello a "públicos afectivos»: formaciones públicas en red que son movilizadas a través de expresiones sentimentales. De ahí que en ellas predominan formas narrativas híbridas que suelen consistir en la remezcla de contenidos mainstream, a través de la cual son representadas afectivamente diferentes subjetividades (Chadwick, 2013). En principio, la actividad online facilita la formación de públicos en red alrededor de comunidades, ya sean reales o imaginadas (Howard y Hussain, 2013). Pero hay quienes apuntan que más bien producen «sentimientos de comunidad» o «el sentimiento de ser contado» (Coleman, 2013) y por tanto incorporado a la cosa pública. Más que acción colectiva, estamos ante una acción conectiva (Bennett y Segerberg, 
2012); una conectividad emocionalmente recargada. Y es interesante anotar que la participación del ciudadano en las redes sociales contiene un elemento de performance, en la medida en que se hace algo pero al mismo tiempo se señala, subraya y adorna la acción misma (Schechner, 2002). Las redes son así espacios afectivos.

\section{VIRTUDES DE LA DIGITALIZACIÓN}

En conjunto, pues, parece que habría que valorar negativamente el impacto de las nuevas tecnologías de la información sobre la conversación pública, que habría pasado de la desatención pasiva al histerismo activo. Su contribución a la sentimentalización de la democracia no sería, por tanto, desdeñable. Sin embargo, conviene recelar de juicios tan unívocos. En última instancia, las nuevas tecnologías de la información responden en sus efectos al rasgo característico de la tardomodernidad, que es la fase durante la cual la modernidad descubre la naturaleza de sus efectos, o sea: la ambivalencia.

Sucede que cualquier valoración positiva de las redes sociales como espacios políticos donde los ciudadanos se comunican y conectan dialógica y afectivamente presupone un cuestionamiento del modelo clásico de la opinión pública. Papachaarissi (2015:26) es explícito al respecto: «Este enfoque asume que las democtacias están basadas en la racionalidad, cuando, de hecho, son empresas caóticas dirigidas por aspiraciones de racionalidad, atrapadas en una puesta en escena diaria de ethos, pathos $y$ logos». Desde esta perspectiva, el enfoque habermasiano, con su énfasis en la deliberación pública, adolecería de falta de atención a la realidad sociológica y se beneficiaría por ello de una mayor atención a las circunstancias socioculturales de los ciudadanos (Dahlgren, 2009: 5). Los espacios híbridos de la digitalidad inducen nuevos hábitos cívicos que se desvían del ideal deliberativo, pero que pueden interpretarse como democratizadores en la medida en que propician un giro afectivo que es, por definición, inclusivo. Aunque la pluralización digital no es inherentemente democratizadora, las redes sociales dan visibilidad a voces marginadas por el mainstream (Bimber, 1998; Berry, Kim y Spigel, 2010). Asimismo, generan nuevas oportunidades para la movilización colectiva, como demostrarían los movimientos antiausteridad europeos y norteamericanos, cuyo éxito no puede explicarse sin aludir a la dimensión afectiva de las redes digitales; en este caso, mediante la difusión de mensajes emocionalmente recargados orientados a activar la indignación como sentimiento político primario. Esta activación está vinculada a la autoidentificación del ciudadano así movilizado como víctima de una injusticia que demanda reparación. Pero más que estructuras deliberativas, hablamos de espacios de convergencia emocional donde los lazos afectivos pesan más que la persuasión racional. Es por eso que la potencia- 
lidad inclusiva de los afectos políticos comunicados a través de las redes digitales posee una clara contrapartida: experimentar ciertas emociones no es tener razón. En otras palabras, la inclusividad puede cobrarse un alto precio cuando se logra a través de la emocionalidad política.

Por otro lado, allí donde unos denuncian la democracia de enjambre, otros, como James Surowiecki (2005), defienden la wisdom of crowds o sabiduría de las masas, a la vista de la capacidad de ciertos arreglos institucionales para procesar información de manera correcta. No sólo el mercado; también Wikipedia (Arias Maldonado, 2009). La interacción entre individuos, que la red facilita extraordinariamente al rebajar dramáticamente los costes de transacción, produciría mejores resultados que su acción separada. Los mecanismos de agregración informal en que también consisten las redes poseerían, desde este punto de vista, ciertas virtudes epistémicas.

Si nos limitamos al terreno de la expresión de opiniones políticas o morales, es evidente que la red amplía las posibilidades de influencia a un mayor número de ciudadanos, si bien, naturalmente, por razones elementales de escala, la visibilidad dependerá de la habilidad de cada uno de ellos: si todos queremos escribirnos con todos, los famosos 140 caracteres de Twitter son una unidad de atención muy razonable y no el resultado de un deliberada voluntad de simplificación. Más que un diálogo, la red propicia un poliálogo entre múltiples participantes. Y, sin embargo, junto a las redes sociales masivas existen otras más especializadas y profesionales, e incluso dentro de aquéllas es perfectamente posible encapsular comunidades epistémicas o conversacionales alejadas del modelo de reproducción viral. A cambio, la divisoria liberal clásica entre la esfera privada y la pública se ve difuminada por el efecto de unas tecnologías ubicuas de las que puede predicarse una cualidad simultáneamente pública y privada (Athique, 2013: 208). Las redes, pues, facilitan la repolitización de los ciudadanos y son capaces de generar una «sensación participativa» que puede reforzar la legitimidad del sistema democrático.

Así pues, la conversación pública es ahora más rica y realista, a costa de resultar más caótica; las posibilidades de influencia, siempre desiguales, son mayores, dentro de lo que la escala hace posible; y es el aumento de los canales de expresión del pluralismo lo que conduce a la polarización. Quizá hay un problema de expectativas: pensar que las nuevas tecnologías iban a provocar la transubstanciación de las democracias y el público. Simplemente, estamos en una etapa de transición durante la cual la sociedad tiene que adaptarse a una tecnología profundamente disruptiva. Y conviene anotar que esa disrupción, sumada a factores sociales tan diversos como el cambio demográfico y cultural asociado a él, está ligada, en una espiral multicausal de difícil desentrañamiento, a fenómenos más amplios. Por ejemplo, el debilitamiento de los viejos partidos de masas, capaces de establecer una relación directa y continuada con 
amplios segmentos de un electorado fiel que contribuía incluso económicamente a su sostenimiento, obedece simultáneamente al cambio demográfico y a la revolución tecnológica, que ponen en evidencia una rigidez organizativa aparentemente insuperable (véase Wren y McElwain, 2009). Y debilitada su función moderadora, que propicia la aparición de los fringe parties, o partidos insurgentes, genera la aparición de un votante menos fiel pero no necesariamente más pragmático: un swing voter menos racional que emocional. De ahí el período de gracia cada vez más corto del que disfrutan los políticos electos. Se ha llegado a afirmar que los partidos tradicionales están "gobernando el vacío» (Mair, 2013). En buena medida, porque se va abriendo paso un proceso de "personalización de la política» entre cuyas manifestaciones se cuentan el desplazamiento de la acción colectiva coordinada y el ascenso de formas expresivas de acción individual que encuentran en las plataformas digitales su espacio natural (cfr. Bennett, 2012). Se deduce de aquí que las redes sociales no son culpables de todo, ni mucho menos; son, también, reflejo de tendencias más amplias a las que a su vez contribuyen.

\section{MUTACIONES DEMOCRÁTICAS EN LA ERA DIGITAL}

Ahora bien, si las tecnologías digitales llevan adosada una ideología política de manera espontánea, es el rechazo de la mediación representativa en nombre del do it yourself: la participación directa del ciudadano, ya sea esta formal o informal. Este es uno de los efectos más relevantes de la digitalización en curso: su impacto sobre la legitimidad de la mediación. Se produce este en todos los órdenes: cultural (deslegitimación del experto), político (crisis de la representación), económico (lógica del mercado), simbólico (desjerarquización). En gran medida, se trata de una falsa desintermediación. Más bien, asistimos simultáneamente a un cambio en la naturaleza y la situación de las mediaciones y a un ocultamiento de las mismas (cfr. Morozov, 2013). Pensemos en los algoritmos que traducen los datos a significados, en el código que hace posibles algunas cosas pero impide otras, en las mismas plataformas a través de las cuales operamos.

Políticamente, se va abriendo paso la idea de que la vieja concepción del poder, a la vez patrimonial y vertical, está agotando su vigencia en un mundo que presencia la emergencia de nuevos micropoderes (Naím, 2013) que a menudo se sirven de las tecnologías digitales para organizarse: desde movimientos ciudadanos a expertos, pasando por la combinación de ambos. Esta nueva comprensión del poder ha sido sistematizada por Heimans y Timms (2014). Si entendemos por poder la capacidad de producir efectos intencionados, el nuevo y el viejo poder los producen de manera diferente: los nuevos modelos de poder 
se basan en la coordinación colectiva y en la participación masiva, mientras que el viejo obtiene su capacidad de aquello que las organizaciones o las personas saben, tienen o controlan de manera monopolista. Las conductas generadoras de nuevo poder son de distinto tipo: se basan en compartir, en la copropiedad, en financiar proyectos ajenos colectivamente, en la producción de contenidos o productos difundidos a través de las redes sociales, en remezclar contenidos preexistentes para dar forma a productos novedosos. Transparencia, autoorganización, derecho inalienable a la participación, coordinación, afiliación condicional: son algunos de los valores asociados a esta nueva comprensión del poder, llamada a coexistir - más que a desplazar- con la tradicional.

Ahora bien, el protagonismo adquirido por los medios de comunicación durante las últimas décadas a la hora de articular la relación entre representantes y representados, que ha aumentado el poder informal de estos sobre aquellos, ha acentuado la tendencia que nos convierte en algo distinto: en espectadores. En su notable trabajo sobre el tema, Jeffrey Green (2010) lo resume así:

[...] la vasta mayoría de nuestra experiencia política, sea como votantes o como no votantes, no consiste en tomar decisiones y ejecutar acciones políticas, sino más bien en observar y escuchar a otros que se encuentran activamente comprometidos en esas tareas. [...] La mayor parte de los ciudadanos durante la mayor parte del tiempo no son decisores que se relacionan con la política con sus voces, sino espectadores que se relacionan con la política con sus ojos.

De ahí que, a su juicio, no tenga demasiado sentido seguir hablando de la «voz del pueblo»; lo relevante son sus ojos. Pasaríamos así de una democracia vocal a una democracia ocular, en consonancia con el signo de los tiempos. $\mathrm{Si}$, como se señaló anteriormente, el teólogo Johann Michaelis podía escribir allá por 1759 que «la lengua es una democracia» para expresar con ello la importancia de la conversación pública como mecanismo de construcción política, ahora sería la vista la que habría de operar democráticamente. Este ciudadano ocular no decide por sí mismo (como el ciudadano lleno de interés en una democracia directa) ni se inhibe de decidir (como el abstencionista carente de interés alguno), sino que posee plenos derechos políticos pero se relaciona con la política primariamente como espectador: psicológicamente implicado, no lleva una vida política activa. O sea, que sólo una minoría sale a manifestarse, aunque sean muchos los que comentan la actualidad política a través de las redes sociales. Sin embargo, el ciudadano ocular decide. Sobre todo, mediante el voto que pone y quita gobiernos; pero también mediante el apoyo que presta o retira a gobiernos y políticas públicas concretas durante las legislaturas. El ciudadano ocular, podríamos decir, es un voyeur que participa periódicamente en la creación de su objeto de atención. 
Para Green, el problema es qué hacer con esto: cómo dar forma institucional a algún tipo de democracia ocular que traslade el foco de la voz popular a la mirada del ciudadano. Su respuesta es interesante, al apostar por una recuperación del modelo plebiscitario de democracia debidamente corregido. Porque cuando la política concierne al espectador, el objeto principal de atención son los líderes así observados, no las leyes por ellos aprobadas; análogamente, la voz del ciudadano cuenta menos que su mirada, una «mirada del pueblo» orientada al control y la vigilancia de los líderes. Green sugiere que éstos han de aparecer en la esfera ocular, mostrarse ante los ciudadanos, antes que deliberar y negociar en la esfera vocal parlamentaria. Por todo ello, la autonomía del ciudadano no es el ideal de una democracia ocular, sino que lo será la franqueza de los representantes en sus apariciones ante el público. Nuestro autor no confía en la sinceridad bienintencionada de los líderes, sino que apuesta por impedir legalmente que controlen las condiciones de sus propias apariciones públicas. Buen ejemplo de ello sería el question time en el Parlamento británico, donde el intercambio de preguntas y respuestas entre el presidente y la oposición se hace sin papeles y alcanza una indiscutible ferocidad. Algo ingenuamente, Green cree que los líderes estarán obligados a ser francos cuando no estén escenificando; y no escenificarán cuando dejen de controlar los medios de la publicidad política. Es entonces cuando algo parecido a la acción política defendida por Hannah Arendt (1993) podrá tener lugar, siempre ante la mirada sancionadora del público: una revelación del sujeto a través del discurso, un segundo nacimiento que tiene lugar en la esfera pública y en contienda con otros sujetos. Para Green, la clave consiste en obligar a los líderes políticos a contender entre sí ante los ciudadanos y a que lo hagan de una determinada manera: sin corsés, trucos, ni mentiras.

A su juicio, este modelo de democracia es postrepresentativo, ya que los representantes no actuarían sobre la base de preferencias ciudadanas preexistentes, sino que estas preferencias emergen en el marco de la relación ocular que liga a los ciudadanos con sus líderes. Desde este punto de vista, el votante habría de actuar como un lector de literatura modernista: co-creando la obra en el acto de su recepción. Si el problema de una democracia convertida en espectáculo es la calidad del espectáculo, más manipulativo que genuino, la solución de Green es mejorar las condiciones de producción. A tal fin, Green se apoya en la concepción minimalista de la democracia defendida por Josef Schumpeter (2015). Es sabido que el pensador austríaco definía la democracia como aquel mecanismo institucional para llegar a decisiones políticas en el que algunas personas o grupos adquieren el poder de decidir mediante una lucha competitiva por el voto popular. Es una concepción minimalista porque en ella lo importante, junto al aparato constitucional que protege los derechos y libertades individuales, es la existencia de un procedimiento para la elección com- 
petitiva de los gobernantes. Y esto, decisivamente, implica que los gobernados retienen la capacidad para decidir sobre aquellos, que a su vez serán responsables y habrán de rendir cuentas ante los ciudadanos. En este contexto, anota Green, el significado fundamental del mandato popular es la aprobación de leyes coherentes con las opiniones, preferencias y valores de los ciudadanos.

Ahora bien, ¿cómo sabremos si eso ha sucedido, si ese mandato ha sido obedecido o no? La respuesta es tan lógica como insatisfactoria: lo sabremos cuando los ciudadanos renueven su confianza en el gobierno. Pero si no lo hace, también lo sabremos: porque se castigará precisamente a aquel gobierno que no ha respetado esa necesaria coherencia. De manera que la democracia no puede equivocarse, porque las elecciones reflejarán siempre la medida en que los gobernantes han satisfecho las preferencias de los ciudadanos. Pero se trata de una respuesta insatisfactoria por varios motivos. Recordemos que el ciudadano castiga la incoherencia programática que se traduce en una subida de impuestos, pero aplaude a quien preveía subirlos y los bajó; del mismo modo, la mayor parte de las reformas económicas de carácter liberalizador son rechazadas inicialmente y solo aceptadas una vez demuestran su eficacia. $\mathrm{O}$ sea, que las preferencias (como las opiniones y las emociones) son cambiantes. Y lo son porque no son independientes de la acción del gobierno, ni del más general proceso de competencia entre los partidos que se disputan el voto popular. Preferencias, valores y sentimientos son co-creados mediante un proceso en el que intervienen diversas fuerzas: el discurso político de gobierno y oposición, las movilizaciones colectivas, la generación espontánea de opiniones y valores en el seno de la sociedad civil, la reproducción de esos distintos discursos en los medios de comunicación, los propios acontecimientos. Pero hay una jerarquía de fuerzas; no todas esas instancias poseen la misma influencia. Y es obvio que gobiernos y líderes de la oposición tienen más influencia que el resto. Aunque, a su vez, no puedan controlar el efecto de sus mensajes: porque los hay mejores o peores; más o menos eficaces.

Sucede que allí donde lo que cuenta es el efecto sobre el público - creado con el auxilio de técnicas escenográficas y medios de comunicación, cuyo efecto es amplificado por las redes sociales - antes que la calidad de los resultados o la construcción del consenso. Esto implica que la primera cualidad del representante político será la capacidad para la representación dramática. Haciendo uso de ella, el representante intentará establecer una relación directa con los ciudadanos a través de los medios de comunicación, apoyándose en las redes sociales y su efecto de proximidad emocional; una relación visual que opera en el nivel «sensacional» de las impresiones preconscientes e influye sobre la formación de emociones políticas de adhesión o rechazo. De donde se sigue que cuanto más se apoya la práctica de la democracia en su aspecto visual, más plebiscitario es también de facto su funcionamiento. 
Cuando hablamos de los efectos sobre el público, es conveniente ponderar la medida en la cual el cerebro político es ante todo narrativo. Los seres humanos poseen una natural inclinación a estructurar la realidad a través de narraciones o historias que les permiten vincularse afectivamente con los acontecimientos (Westen, 2007). No por casualidad se ha propuesto el principio narrativo - la idea de que los seres humanos piensan, perciben, imaginan y toman decisiones morales de acuerdo con estructuras narrativascomo fundamento para la psicología política, esto es, como herramienta para la comprensión de fenómenos psicológicos como la cognición política, la toma de decisiones, la identificación ideológica o las emociones colectivas (Hammack y Pilecki, 2012). En este contexto, recordemos la crítica que Iris Marion Young hace del deliberativismo racional, acompañado de una demanda de expansión de las formas de expresión aceptables en un contexto democrático: la retórica o el storytelling son a su juicio tan válidas como la argumentación racional, cuya prevalencia daría de otro modo ventaja a los sujetos más capacitados para desarrollarla (Young, 1996). Pues bien, los medios de comunicación digitales convierten los sucesos en happenings, al proporcionar una plataforma donde las distintas operaciones, patrones de relación y procesos de búsqueda de significado tienen lugar, haciendo así posible que el público que forma la red se apropie del suceso mismo (Massumi, 2002; Karatzogianni, 2013).

Ahora bien, cuando tomamos en consideración la influencia de las redes sociales sobre la afectividad de los ciudadanos, hay que recordar que «aunque el sujeto ciudadano haya podido ser un sujeto lector, el ciudadano contemporáneo es un sujeto visual [viewing]» (Panagia, 2009: 19). De ahí que este mismo pensador subraye que la "narratocracia» de nuestros días —el privilegio de la narrativa como género para la exposición de demandas e ideas en el pensamiento político contemporáneo- merezca ser cuestionada. Por ello llama la atención sobre un concepto que no es primariamente político pero adquiere, en nuestras democracias pluralistas, valencia política: el de sensación. Si entendemos por esta una heterogeneidad de impulsos que impactan sobre nuestro cuerpo, interrumpiendo una forma convencional de ver el mundo, las sensaciones se convierten en momentos políticos porque pueden suponer una dislocación de nuestra subjetividad. O sea, una disrupción del régimen de percepción que condiciona nuestra mirada sobre la sociedad y, por tanto, nuestros juicios políticos y opciones electorales. Este trabajo político de la sensación, activado por estímulos de todo tipo, tiene lugar «por debajo y más allá del registro discursivo que tiene sentido comunicativo» (Panagia, 2009: 5). Sucede que en una sociedad pluralista y democrática, individuos y grupos se atienden recíprocamente en el nivel de las apariencias: la vida política se convierte así en una empresa perceptiva. Para Panagia, dentro de todo régi- 
men de percepción existe una micropolítica evaluativa que formula aquellas condiciones compartidas que sirven para dar sentido a las cosas en el interior de cada grupo social (o tribu moral). Resulta de aquí una caracterización de la vida democrática como coexistencia de distintas culturas, cada una de las cuales conlleva un régimen de percepción que condiciona lo que cuenta y lo que no cuenta como experiencia, motivación o intuición. En consecuencia, las condiciones y los procesos de formación de las percepciones individuales — más acá y más allá de la deliberación racional o la transmisión de mensajes articulados- se convierten en inevitable objeto de atención política. $Y$ en una «democracia sensorial» no es posible ignorar la multiplicación digital de los estímulos — visuales, verbales, musicales, ambientales - a los que nos vemos expuestos.

Sea como fuere, parece claro que las nuevas tecnologías intensifican la comprensión de la democracia como contienda por la influencia: influencia sobre el modo en que los ciudadanos perciben o enmarcan determinados asuntos, como presupuesto para el cambio cultural que precede al político. Esto incluye ideas, razonamientos, emociones, estados de ánimo; también sinrazones. Para comprender el proceso político contemporáneo, pues, es conveniente tomar en consideración la dimensión afectiva de las redes sociales y demás plataformas digitales (entendiendo afecto en un sentido amplio que incluye emociones, estados de ánimo y sensaciones). Es a través de las redes digitales que el ciudadano sentimental se convierte en público afectivo, que a su vez constituye la audiencia de la democracia ocular y es sujeto receptor de sensaciones susceptibles de alterar su mapa perceptivo. En este contexto, el representante político no desaparece, sino que se convierte en uno de los actores privilegiados dentro de la compleja malla de interacciones en que se convierte la vida democrática; privilegiado en la medida en que su voz y sus acciones poseen más visibilidad y por tanto más potencial influencia que la de otros.

\section{CONCLUSIÓN}

¿Qué consecuencias tiene para la democracia el proceso de digitalización que está transformando de manera acelerada la economía, la cultura y aun nuestros hábitos y percepciones cotidianas? Hay muchas formas de responder a esta pregunta, porque muchas son los modos en que puede abordarse el análisis de semejante tema. En este trabajo, la atención se ha centrado sobre la digitalización de la conversación pública, vale decir, sobre el modo en que los ciudadanos participan en la esfera pública socializándose en los asuntos públicos, discutiendo sobre ellos y movilizándose en compañía de otros con objeto 
de reivindicar una u otra posición sobre los mismos. Tal como se ha señalado, la opinión pública posee una dimensión prescriptiva que remite a la forma en que el debate público debería conducirse: como una deliberación racional entre ciudadanos que sirve para refinar el uso público de la razón. Sin embargo, este ideal de raigambre ilustrado no parece realizarse fácilmente en las democracias realmente existentes, últimamente marcadas de hecho por el ascenso de los populismos y una creciente polarización ideológica que a menudo desemboca en dinámicas vetocráticas. Este trabajo trata de esclarecer de qué manera está contribuyendo a esa tendencia la generalización de las redes sociales como instrumento habitual de comunicación y conexión intersubjetiva.

A tal fin, se han combinado dos giros aún recientes en las ciencias sociales. Por un lado, el giro digital que trata de dar cuenta del impacto de las nuevas tecnologías de la comunicación; por otro, el giro afectivo que se ocupa de elucidar cuál es el papel que las emociones y demás procesos preconscientes juegan en la percepción y toma de decisiones individuales (incluyendo la percepción de los asuntos públicos y la toma de decisiones políticas, así como el efecto colectivo de su agregación). De acuerdo con la literatura sobre los afectos políticos, los individuos no son sujetos soberanos, sino víctimas de sesgos cognitivos y emocionales que influyen sobre su agencia individual. Así las cosas, nos hemos preguntado de qué manera contribuyen las redes sociales y la conectividad digital a la formación de afectos políticos. La respuesta es que las nuevas tecnologías de la información son intrínsecamente afectivas, por cuanto en ellas priman el uso expresivo y la vinculación emocional, que puede cautamente describirse con arreglo a la metáfora del contagio. El sujeto conectado es un sujeto afectivo que experimenta sentimientos de comunidad en su contacto con formaciones más o menos fluidas en torno a asuntos o problemas concretos, al tiempo que se adscribe a una tribu moral concreta y desarrolla el consiguiente antagonismo hacia grupos sociales rivales. Esta realidad obliga a revisar el moderlo habermasiano de opinión pública, por cuanto la inclusión y la participación son menos deliberativas que sentimentales, más «sensacionales» que persuasivas.

$\mathrm{Si}$ a la digitalización le sumamos fenómenos tales como el creciente pluralismo social y el vigor de una cultura de masas de matriz audiovisual, nos encontramos con una mutación de la democracia liberal-representativa digna de atención teórica. No es que esta deje paso a formas postrepresentativas de articulación democrática, pero sí es claro que tanto la relación representativa como la acción política están experimentando cambios que justifican la búsqueda de nuevas categorías capaces de dar cuenta de los mismos. Se discuten así al final del trabajo las nociones de democracia ocular (conforme a la cual la relación representativa se basa menos en la voz del pueblo que en su mirada sobre el desempeño de los representantes, lo que acentúa su cualidad plebiscitaria) y democracia sensorial (que, asentada igualmente sobre la condición 
visual del ciudadano contemporáneo, alude a los estímulos y sensaciones que modifican nuestras percepciones sociales, lo que les concede relevancia política). La generalización de las nuevas tecnologías de la información no puede sino reforzar los procesos descritos por estas categorías.

\section{Bibliografía}

Arendt, H. (1993). La condición humana. Barcelona: Paidós.

Arias Maldonado, M. (2009). Planeta Wikipedia. Revista de Libros, 155, 3-7.

Athique, A. (2013). Digital Media and Society. An Introduction. Cambridge: Polity.

Beer, D. y Burrows, R. (2013). Popular Culture, Digital Archives and the New Social Life of Data. Theory, Culture \& Society, 30 (4), 47-71. Disponible en: http://dx.doi. org/10.1177/0263276413476542.

Bennett, W. L. (2012). The personalization of politics: political identity, social media, and changing patterns of participation. The Annals of the American Academy of Political and Social Science, 644 (1), 20-39. Disponible en: http://dx.doi.org/10.1177/0002716212451428.

Bennett, W. L. y Segerberg, A. (2012). The logic of connective action: Digital media and the personalization of contentious politics. Information, Communication and Society, 14 (6), 770-799. Disponible en: http://dx.doi.org/10.1080/1369118x.2012.670661.

Berry, C., Kim, S. y Spigel, L. (2010). Electronic elsewheres: Media technology and the experience of social space. Minneapolis: University of Minnesota Press.

Bimber, B. (1998). The Internet and political transformation: Populism, community, and accelerated pluralism. Polity, 31 (1), 133-160. Disponible en: http://dx.doi. org/10.2307/3235370.

Brader, T. y Marcus, G. (2013). Emotion and Political Psychology. En L. Huddy et al. (comps.). The Oxford Handbook of Political Psychology, 2a ed. (pp. 165-204). Oxford: Oxford University Press. Disponible en: http://dx.doi.org/10.1093/oxford$\mathrm{hb} / 9780199760107.013 .0006$.

Canavagh, A. (2007). Sociology in the Age of the Internet. London: Open University Press.

Caplan, B. (2008). The Myth of the Rational Voter: Why Democracies Choose Bad Policies. Princeton: Princeton University Press.

Castells, M. (1996). Information Age: Rise of the Network Society, vol. 1. Malden: Wiley-Blackwell.

- (2008). Comunicación y poder. Madrid: Alianza.

Chadwick, A. (2009). Web 2.0: New challenges for the study of e-democracy in an era of informational exuberance. Journal of Law and Policy for the Information Society, 5 (1), 9-41.

- (2013). The hybrid media system: Politics and power. London: Oxford University Press. Disponible en: http://dx.doi.org/10.1093/acprof:oso/9780199759477.001.0001.

Coleman, S. (2013). How voters feel. Cambridge: Cambridge University Press.

Dahlgren, P. (2009). Media and political engagement. Cambridge: Cambridge University Press.

Flew, T. (2002). New Media: An Introduction. Melbourne: Oxford University Press.

— (2008). New Media: An Introduction. Oxford: Oxford University Press. 
Fraser, N. (1992). Rethinking the Public Sphere: A Contribution to the Critique of Actually Existing Democracy. En C. Calhoun (comp.). Habermas and the Public Sphere (pp. 109142). Cambridge: MIT Press.

Fuchs, C. (2008). Internet and Society. London and New York: Routledge.

Gladwell, M. (2010). Small Change: Why The Revolution Will Not Be Tweeted. The New Yorker, 4 de octubre.

Green, J. (2010). The eyes of the people: democracy in an age of spectatorship. Oxford: Oxford University Press.

Greene, J. (2013). Moral Tribes. Emotion, Reason, and the Gap between Us and Them. London: Atlantic Books.

Gregg, M. (2011). Work's intimacy. Cambridge: Polity.

Habermas, J. (1981). Historia y crítica de la opinión pública. La transformación estructural de la vida pública. Valencia: Gustavo Gili.

Haidt, J. (2012). The Righteous Mind. Why Good People are Divided by Politics and Religion. London: Penguin.

Hammack, P. y Pilecki, A. (2012). Narrative as a Root Metaphor for Political Psychology. Political Psychology, 33 (1), 75-103. Disponible en: http://dx.doi.org/10.1111/j.14679221.2011.00859.x.

Han, B. (2013). Im Schwarm. Berlín: Matthes and Seitz.

Heimans, J. y Timms, K. (2014). Understanding 'New Power'. Harvard Business Review, diciembre.

Hölscher, L. (1978). Öffentlichkeit. En O. Brunner, W. Conze y R. Koselleck (comps.). Geschitliche Grundbegriffe. Historisches Lexikon zur politisch-sozialen Sprache in Deutschland, vol. 4 (pp. 413-468). Stuttgart: Klett-Cotta.

Howard, P. N. y Hussain, M. (2013). Democracy's fourth wave? Digital media and the Arab Spring. New York: Oxford University Press. Disponible en: http://dx.doi.org/10.1093/ acprof:oso/9780199936953.001.0001.

Hug, T. (2013). On the Medialization of Knowledge in the Digital Age. International Journal of Humanities and Social Science, 3 (11), 22-35.

Kahneman, D. (2011). Thinking, fast and slow. London and New York: Allen Lane.

Karatzogianni, A. (2013). A cyberconflict analysis of the Arab Spring. En G. Youngs (comp.). Digital world: Connectivity, creativity and rights (pp. 159-175). London: Routledge.

Klemperer, V. (2007). LTI: Notizbuch eines Philologen. Stuttgart: Reclam.

Krause, R. (2011). Bodies in Action: Corporeal Agency and Democratic Politics. Political Theory,39(3),299-324. Disponibleen: http://dx.doi.org/10.1177/0090591711400025.

Mair, P. (2013). Ruling the Void. The Hollowing of Western Democracy. London: Verso.

Manovich, L. (2014). Software takes command. London: Bloomsbury Academic.

Mansbridge, J. (1990). Feminism and Democracy. American Prospect, 1, 126-139.

Massumi, B. (2002). Parables for the virtual: Movement, affect, sensation. Durham: Duke University Press. Disponible en: http://dx.doi.org/10.1215/9780822383574.

McLuhan, M. (1962). The Gutenberg Galaxy: The Making of Typographic Man. Toronto: University of Toronto Press. 
Miller, P. R. (2011). The Emotional Citizen: Emotion as a Function of Political Sophistication. Political Psychology, 32, 575-600. Disponible en: http://dx.doi.org/10.1111/ j.1467-9221.2011.00824.x.

Morozov, Evgeny (2013). To Save Everything, Click Here. Technology, solutionism and the urge to fix problems that don't exist. London: Allen Lane.

Naím, M. (2013). The End of Power. From Boardrooms to Battlefields and Churches to States, Why Being In Charge Isn't What It Used to Be. New York: Basic Books.

Neuman, W. R., Marcus, G. E., Crigler, A. N. y Mackuen, C. (2007). Theorizing Affect's Effects. En W. R. Neuman et al. (comps.), The Affect Effect. Dynamics of Emotion in Political Thinking and Behavior (pp. 1-20). Chicago and London: University of Chicago Press. Disponible en: http://dx.doi.org/10.7208/chicago/9780226574431.003.0001.

Orwell, G. (2000). Essays. London: Penguin.

Panagia, D. (2009). The Political Life of Sensation. Durham and London: Duke University Press. Papacharissi, Z. (2015). Affective Publics. Sentiment, Technology, and Politics. Oxford: Oxford University Press.

Popkin, S. (1994). The Reasoning Voter: Communication and Persuasion in Presidential Campaigns. Chicago: University of Chicago Press.

Poster, M. (1995). The Second Media Age. Cambridge: Polity.

- (2006). Information please: culture and politics in the age of digital machines. Durham and London: Duke University Press. Disponible en: http://dx.doi.org/10.1215/9780822388470.

Rawls, J. (1993). Political Liberalism. New York: Columbia University Press.

Reese, S. et al. (2007). Mapping the Blogosphere: Professional and Citizen-based Media in the Global News Arena. Journalism, 8 (3), 235-261. Disponible en: http://dx.doi. org/10.1177/1464884907076459.

Rosenberg, S. (2014). Political Psychology. En M. T. Gibbon (comp.). The Encyclopedia of Political Thought (pp. 2792-2793). Malden: Wiley-Blackwell.

Sartori, G. (2005). Elementos de teoría politica. Madrid: Alianza.

Schechner, R. (2002). Performance studies: An introduction. New York: Routledge.

Scherer, K. (2005). Unconscious process in emotions: The bulk of the iceberg. En L. Barrett et al. (eds.). Emotion and Consciousness (pp. 332-344). New York: Guilford.

Schumpeter, J. (2015). Capitalismo, socialismo y democracia, vol. 2. Barcelona: Página Indómita.

Scott, L. (2015). The four-dimensional human. Ways of Being in the Digital World. London: William Heinemann.

Standage, T. (2013). Writing on the Wall. Social Media, The First 2000 Years. London: Bloomsbury Publishing.

Sunstein, C. (2008). Republic.com 2.0. Princeton: Princeton University Press.

Surowiecki, J. (2005). The Wisdom of Crowds: Why the Many Are Smarter Than the Few. New York: Abacus.

Tocqueville, A. de (2005). La democracia en América. Madrid: Alianza.

Ward, I. (2014). Public Sphere. En M. T. Gibbon (comp.). The Encyclopedia of Political Thought (pp. 3051-3059). Malden: Wiley-Blackwell.

Webster, F. (1995). Theories of the Information Society. London: Routledge.

- (2006). Theories of the Information Society. London and New York: Routledge. 
Westen, D. (2007). The Political Brain. The Role of Emotions in Deciding the Fate of the Nation. New York: Public Affairs.

Wetherell, M. (2012). Affect and Emotion. A New Social Science Understanding. London: Sage.

Wren, A. y McElwain, K. (2009). "Voters and parties». En R. Goodin (comp.). The Oxford Handbook of Political Science (pp. 365-391). Oxford: Oxford University Press.

Young, I. M. (1996). Democracy and Difference: Contesting the Boundaries of the Political. Princeton: Princeton University Press. 